Scientific Visualization, 2021, volume 13, number 2, pages 10 - 23, DOI: 10.26583/sv.13.2.02

\title{
Development of a Matrix Tool for Visual Market Research in Strategic Management
}

\author{
N.N. Krupina ${ }^{1}$ \\ St. Petersburg State Agrarian University, St. Petersburg, Pushkin \\ ${ }^{1}$ ORCID: oooo-0002-7983-845X, Krupina n17@ mail.ru
}

\begin{abstract}
A dynamic market environment and active digitalization require an increase in the scientific level of tools for making strategic management decisions. Of particular importance is the intuitive matrix method of visual research of strategic management zone (SMZ), which is understandable to specialists. On the basis of the classical matrices «market - product» and «buyer - seller», the hypothesis of the feasibility of using an additional structured diagnostic test to increase the validity and reliability of the strategy choice is investigated. The test covers a wide range of factors and allows you to comprehensively reflect the current state of the enterprise in the field of demand, assess the resource potential and position relative to competitors. An illustrative example discusses a double matrix technique for visual analysis of the introduction of a new product (non-drinking water) to the market. Taking into account the advantages of matrices as an analytical tool and their potential from the point of view of visualizing the subject area of the professional task under study, possible effective graphic images are considered that reduce the difficulties of perceiving the data array, speed up and facilitate the work of an expert, and increase the reliability of solutions.
\end{abstract}

Keywords: strategy, strategic management zone, decision selection, matrix, visual matrix study, double matrix analysis technique, market, product, diagnostic test, infographics.

\section{Introduction}

Today, many successful companies in competitive confrontation give strategic priority to the ability of top management to choose a creative path of market positioning, mobilizing the resources and initiatives of team members to create the future in a creative and socially responsible manner [1]. This is facilitated by the possession of matrix tools - an ordered sequence of procedures for collecting, systematizing, analyzing an array of data, forming two key comparison criteria and their boundary values, and clearly identifying alternative business processes. Strategic matrices are the primary form, and often the starting point, of visual research, due to their clarity, accessibility, comfort, and intuitive clarity. More than 50 matrices are described, of which the Boston, SWOT, and nominal matrices are widely known (for example, the Abel, Ansoff, McKinsey, Porter, Steiner, and Hofer matrices).

Despite the controversial nature, the sufficient level of knowledge and development of the matrix approach to strategic management, interest in it does not decrease, and the ways of improvement are associated with the unrealized («hidden»[2]) potential of information technologies, which allows users to:

- move from the classic two-dimensional to three-dimensional space with additional dimensions and a variable coordinate system that combines quantitative and qualitative indicators, for example, using the software product «5dchart» [3];

- implement the principles of «visual management» and «simplification of schemes» [4] in the presentation of corporate strategy as a complex object;

- supplement the toolkit with new techniques for integrating visualization methods [5-6], related to the actual need for graphical support of the subject essence of the analysis, taking 
into account changes in the market situation, territorial, industry, production and technological features of the object of study [7];

- adapt techniques for improving the efficiency of information perception (reading speed, improving the accuracy of problem solving, reducing errors [5, 8] when using business analytics software (Big Data, Google Analytics, R-Studio, Business Intelligence, Operational Data Store, etc.) through thoughtful color coding [8, 9], compositional construction [10] and changing the basic shape of diagrams.

We share the opinion that overcoming the insufficient substantiation of the chosen decisions in the process of graphic research of complex socio-economic phenomena is achieved both due to the high speed of visual perception, and through the purposeful interpretation of images based on the preliminary awareness of the user, attracting multi-level information (technological, linguistic, genre, ideological , aesthetic, legal).

Hypothesis: the strategic matrix, as the primary method of visual market research within the specified boundaries of the two-factor model, retains the ability to improve the quality of analytical understanding of the subject area by including an additional diagnostic test in the program apparatus of the preliminary stage of data preparation, structuring the array of initial data in accordance with the causal logic set by the type of a specific strategy.

The purpose of the study is to consider in general terms the possibility of increasing the reliability of the choice of the strategic management zone (SMZ) in the process of matrix visual market research by introducing a diagnostic test. The methods of analysis and synthesis, a systematic approach, sociological research, and the study of statistical and reporting data are used. The theoretical and methodological basis of the study was both the works of economists engaged in strategic planning issues, and the work of scientists in the field of infographics.

For example, in the series of publications by I.K. Romanova, new approaches to the visualization of parametric studies in the framework of multi-criteria problems are discussed, which allow us to determine possible compromise solutions, areas of sensitivity, mutual and dominant influence of parameters, and possible losses in compromise solutions. In addition to traditional visualizations (3-D graphics, contour lines, gradient fields, Andrews curves, parallel coordinates), new visuals are offered (color schemes, radial compass plots, HivePlots image, display of four criteria using the scatter command), which undoubtedly can support decision-making based on matrix analysis. At the same time, the researcher names possible difficulties in the perception (distinctness) of images and warns that the question of choosing visualization tools is closely related to the peculiarities of its perception by a person and his general abilities, and not with specific implementations (rotation of graphic objects and other spatial manipulations). We agree that the presence of some subjective factor forces us to choose more carefully attractive visualizers that correspond to the economic nature of the presented initial data, but does not exclude the need to develop matrix tools.

\section{Visual market position research}

The steadily developing segments of the consumer market demonstrate the applied nature of the strategic planning ideology. Therefore, the confirmation of the hypothesis will be carried out on the example of the choice of the SMZ and the trajectory of the market promotion of the product by a double matrix visual study. The positioning of the product in each quadrant of the matrix means a specific situation that allows the application of a typical strategy of business behavior and the concentration of resources on the most important processes of reproduction of the commercial cycle. Specialists study the market environment of the enterprise in terms of external trends, opportunities and changes that occur in various areas and spheres of life [11].

We use the «product-market» and «buyer-seller» matrices. 
The first "product - market" matrix is a well-known simplified model of the market according to Igor Ansoff's version (1957), orienting business processes towards achieving synergy of interaction between the market environment and the product. The matrix coordinates two factors:

1. Existing and new products. The first one has a history and culture of sales, the second one is planned to be «introduced to the market» to reach a new target audience or expand an existing group of consumers.

2. Existing and new markets. At the first stage, the manufacturer is already operating, has a reputation, at the second, there is a lack of work experience, but a potential group of consumers is predicted, which can become a promising target audience.

«Product novelty» is associated with the emergence of additional functions, modification, replacement of raw materials, the formation of a new customer segment, «market novelty» with new territories or new market segments.

There are four possible SMZ with appropriate strategies:

- existing product and existing market. The strategy of market penetration (improvement of activity), allows the agent to strengthen the market position through the development of the marketing complex: expanding sales channels, increasing sales volume through a flexible pricing policy, more active advertising, new staff competencies, increasing the number of customers, the frequency of use of the product and opening new areas of its application. The obvious strategy is aimed at strengthening positions by increasing market coverage, and the probability of success is high (50\%).

- an existing product in a new market. The market development strategy allows to increase the market coverage through the development of new territories, sales channels, customer groups and other measures to promote a well-known product in new areas of life. Extensive growth is associated with significant costs and risks, and is focused on an external support mechanism. However, the expansion strategy has the greatest potential: by attracting new consumers, it is possible to maintain the existing rates of market promotion and increase profits in the long term. The probability of success is estimated at 20\%;

- a new product in a new market. The highly costly and most complex diversification strategy allows you to promote a new product to new geographic and target markets; it is aimed at simultaneously renewing the source resource and attracting new buyers [12]. Diversification generates a synergy effect and promotes the redistribution of high business risk by increasing the "product portfolio" and the number of territorial markets. However, the likelihood of success is rated very low (5\%);

- a new product in an existing market. A product development strategy, or product expansion, means developing and improving a product for existing consumers in existing markets. The increase in sales is due to the transition to new (non-traditional or additional) functions and properties, changes in packaging, weight, and configuration. Consumers are already familiar with the brand and have formed their attitude to it. The probability of success of the strategy is estimated at $33 \%$.

According to Ansoff, the choice of strategy is based on the principle of least cost, as a variant of the least resistance to the promotion of goods to the market. The priority is the strategy of penetration into the existing market, followed by the strategy of development of the new market. If it is impossible to implement these strategies, less expensive options are considered - the development of a new product and diversification.

In our opinion, in modern conditions, the choice is increasingly based on the search for the maximum degree of coordination of the strategy with the goals of the enterprise: a) increase in production and sales (increase in revenue); b) increase in profit; c) cost reduction; d) market share expansion; e) focus on the implementation of a non-commercial socially or environmentally significant project.

The second «buyer-seller» matrix is less popular, but, in our opinion, from the position of searching for «your customer», it allows you to reliably coordinate the designated product 
strategies with the interests of consumers by comparing the value of the product to the customer with the sales price, which determines the manufacturer's income. The markets remain the same (existing and new), and the seller's income can be either low up to a loss, or high or acceptable.

We will describe the possible strategic positions in this matrix:

- the existing market and low-profit or unprofitable activities. This position is defined as «the country of fools». Manufacturers convince customers to buy unnecessary and unprofitable products for themselves. In ordinary commodity markets, the activity of producing a new product turns out to be low-profitable. Commodity producers, without the necessary competencies and technological advantages, incur losses, do not reinvest profits in the modernization of production, i.e. they do not effectively manage costs, do not have a well-thought-out price behavior;

- a new market and low-income or unprofitable activities. The position is defined as "bait for the buyer". Low-profit activity of a commodity producer in a new market is possible in situations: a) the volume of effective demand in the region is insufficient for a return on investment; b) the number of competing commodity producers attracted by the prospects of demand growth turned out to be excessive; c) the seller uses ineffective production and sales technologies, which are replaced by more progressive, but financially less affordable; d) the offer price does not suit the majority of unmotivated consumers; e) the activation of the market is started prematurely, before the production costs are brought into line with the real level of market prices;

- the new market and high or acceptable operator revenue. The position is defined by us as the "optimal strategic choice», which means the establishment of a long-term mutually beneficial relationship between the seller and the buyer as a result of a clear focus on the real needs of the market. The producer competently conducts market segmentation, divides consumers into certain groups according to the volume and frequency of purchases, and sets appropriate prices for each of them. This tactic helps to form a «core of reference customers». If the demographic, status, and age factors are insignificant, segmentation can be based on flexible pricing and additional services. The cost of the product consists of the profitability of the methods of its production, transportation and availability of electricity. For the reference "customer segments», prices are determined taking into account the stimulating «coefficient of change», which in turn can be set based on the ratio of annual consumption volumes. This is an ideal situation when a commodity producer is accompanied by commercial success, so it can be considered as a priority for the market promotion of operators. The trusting attitude of sellers to buyers is based on an understanding of their desires, habits and needs;

- the existing market and the high or acceptable income of the operator. The position is defined as a «trap for the buyer». The quality of the goods does not correspond to the price, the client does not receive the required benefit, corresponding to his expenses and interests, because commodity producers massively use non-progressive production technologies.

Consider an example of the market positioning of non-drinking water as a commercial product. The novelty of the product is determined by the technology of its production by processing "gray waters». Household, rainwater, industrial, salt-containing artesian water after a complex special treatment is reused in washing and household processes. The producers of the product are water utilities, private operators, enterprises with specialized water treatment technologies, and their competitors are large water utilities that supply industrial water using traditional technologies. The priority target group of clients are cottage owners, agricultural farmers, car wash owners, cleaning companies, municipal services, water users focused on reducing the «water footprint» and water conservation [13]. So, about 40 million cubic meters of water is spent on the annual spring cleaning of streets, bridges, and buildings in Moscow. In some countries, from 25\% to 50\% of household water needs for toilets, car washes, and yard cleaning are covered by the disposal of storm water [14] and municipal wastewater [15]. Abroad, the increase in demand for non-potable water is caused 
by the legislative regulation of the waste water recovery process and innovations in water treatment [16]. For Russia, it is a new market and a new product that has not yet been massively implemented in cities and has not been tested by time, but its development is inevitable due to its multifunctionality (economic, environmental, recreational, ecosystem functions) and the growing global water crisis.

The modern economy proceeds from the fact that the seized water, which has lost its ecological and hydraulic connection with the natural object, becomes a commodity and material value for which the consumer is obliged to pay. Thus, the sale of non-potable water produced from waste water, as a SMZ, is distinguished by the independence of economic activity, goalsetting, planned nature, the presence of a competitor, and orientation to a certain market segment. It remains possible for the product to enter existing regional industrial water markets and reach traditional consumers.

Combination of the considered matrices allows you to visualize the vector of market promotion of the product from the positions of «new product» in the current and new markets to the position of «optimal strategic choice» (Fig. 1). This is a difficult-to-achieve, but the most desirable situation of long-term mutually beneficial harmonious relations and social responsibility. The buyer meets their needs in price and quality, the manufacturer receives a decent income, the regulator provides support (government orders, access to «long investments», social advertising). The selection is marked by a point in the plane of the second matrix. In this example, the first matrix represents the ratio of resources, costs, and revenue, and the second matrix represents consumer behavior as a response to flexible pricing and quality of service. The optimal strategic choice involves the implementation of cost strategies - the strategy of diversification and the strategy of product development.

Combining the matrices, choosing the market position and the corresponding strategy is the final stage of visual research. This graphic technique seems simple and easy only at first glance. In essence, the solution is the result of a complex professional analysis of cause-andeffect relationships, identifying reserves, detailing risks in different markets, and predicting the level of costs of the seller and the buyer. The evidence of the relevance of the selected factors of the matrix study is the identified trends and patterns, developed forecasts, and expert opinions. To trace complex relationships, it is important to maintain control and ease of perception of monotonous series of numbers, texts, regulations, forecasts, and expert assessments.

The crucial step is to select the groups of factor specialization and justify the required level of detail of the indicators and the boundary values of the range of their changes. It is important to balance a set of characteristics: on the one hand, the finer the level of detail, the higher the content and flexibility of the analysis, as well as the lower the energy consumption for processing information [17], but, on the other hand, the objective high redundancy of the source data tires the expert. Schemes, signs, diagrams minimize efforts and preserve the integrity of perception of a particular problem in the course of solving a cognitive task by activating associations when working with a readable and aesthetically illustrated text [5]. 


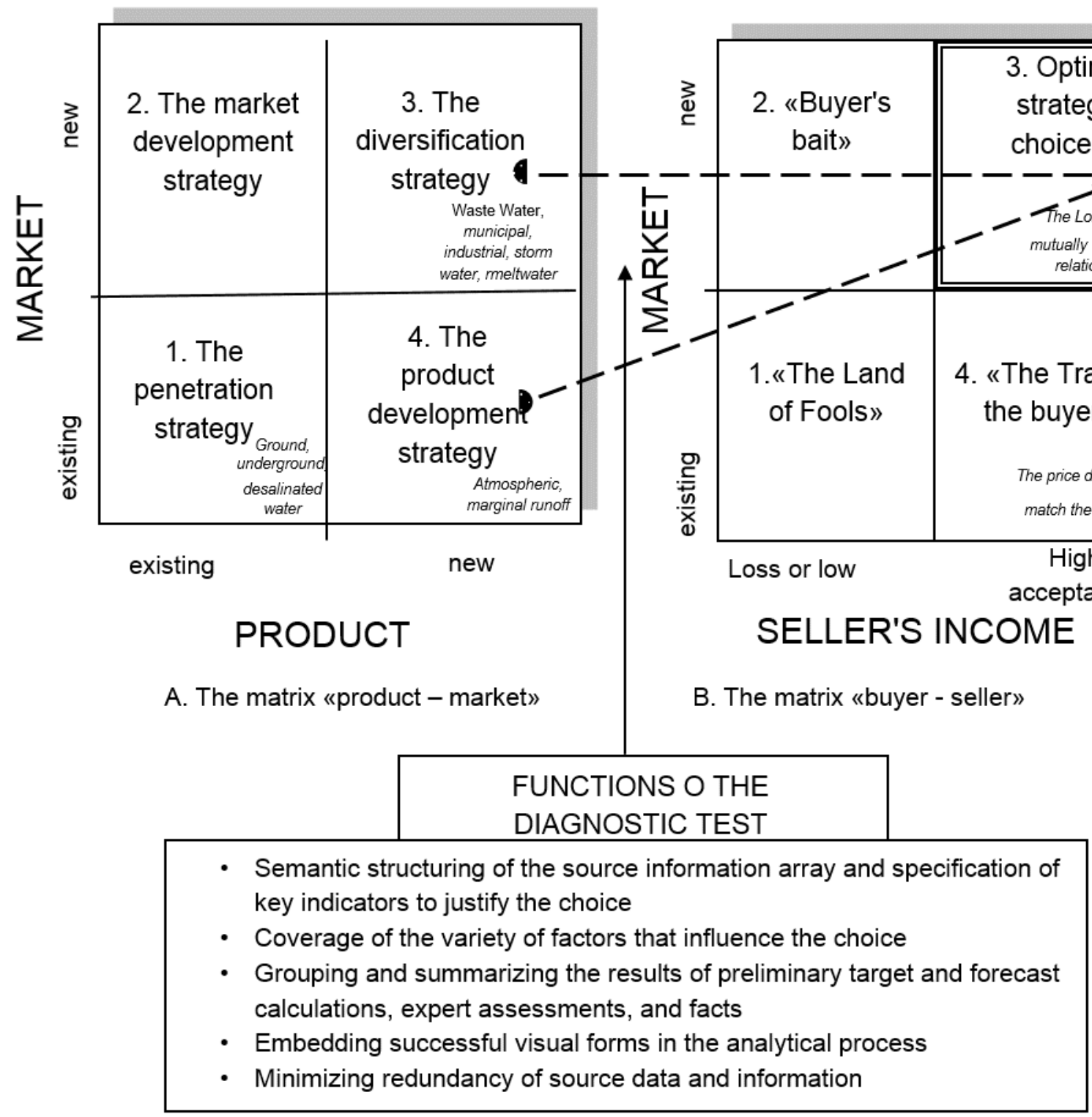

Fig. 1. Visual study of the SMZ by double matrix analysis

We have identified three groups - market, product and resources (Fig. 2). Let's describe the priorities of diagnostics:

1. The market. In business processes, it is important to understand the capacity, growth and concentration of the market, the sales forecast, the relative market share of business units and their ratio to the leading competitor. The market can be high-growth, slowing (but growing), stagnant and declining, as well as non-concentrated, moderately concentrated and highly concentrated. A high-growth and non-concentrated industry market is characterized by significant market strength, low entry barriers, blurred boundaries of product segments, and higher profitability, which together creates the best conditions for its development. Enterprises with a sufficient resource base have a large variability of actions. The probability of risk in such a market is significantly reduced, and the approach of the relative market share to 1.0 (more than 0.75) indicates its sufficient competitive strength of the product (enterprise), primarily in terms of costs. It is important to assess the ratio of the dynamics of key indicators: the growth rate of profit should outpace the growth rate of revenue, which in turn should exceed the growth rate of costs (the «golden rule»). Even a small excess (0.5-1.5\%) indicates a high probability of economic growth and sufficient manageability of the risk of a strategic gap. 


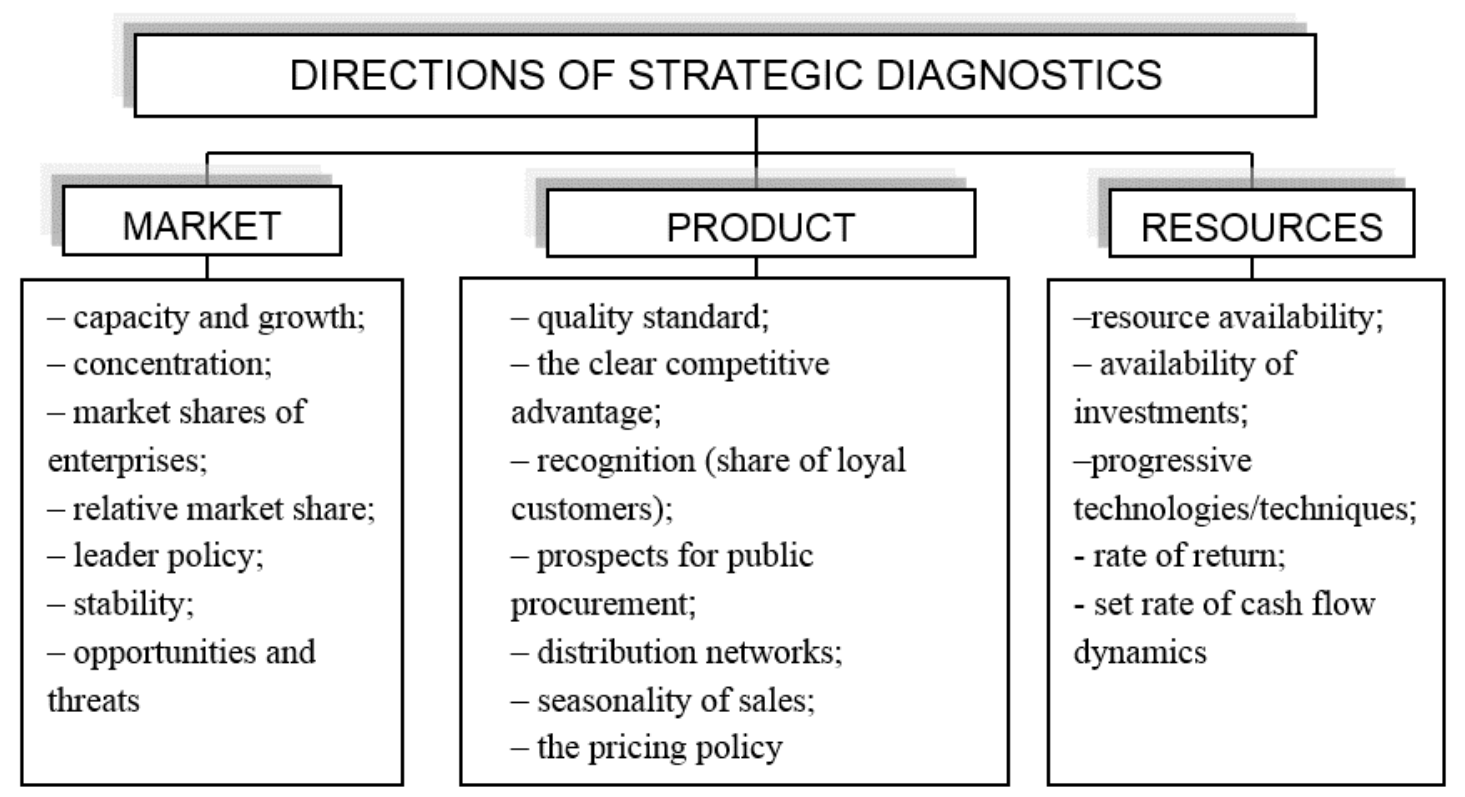

Fig. 2. Priorities of strategic diagnostics (testing)

2. Product. The estimated indicators should disclose the essence of the proposed product - the nature of use, technology, parameters, applications, operating conditions, assortment.

3. Resources. A prerequisite for the implementation of any strategy. The slowdown in business processes due to COVID-19 has shown that the conclusion that the growth of business activity remains unchanged even with favorable market conditions in the past is not always justified. Diagnostics of the resource potential of the enterprise should be multifaceted, multi-level, carried out only on significant indicators, the number of which is not limited.

The list of evaluated aspects for each direction is not final, it can be supplemented, individual issues can be combined in a certain way, corresponding to a combination of factors. The goal is to take into account the requirements of scientific validity, maximum formalization, excluding errors, clarity and accessibility, and the possibility of transformation when changing organizational tasks [18]. The above confirms our hypothesis and allows us to conclude that the quality and efficiency of analytical work depends on the availability of specialized software and a set of interface templates for preliminary testing. Modern business intelligence systems are able to quickly accept and transform data into key indicators and characteristics, which facilitates the construction of hypotheses and forecasting, accelerates comparative assessments, and increases the reliability of decisions. Templates for the transition from a monotonous data flow to graphic forms that hold attention, preserve clarity of thought and compress the «ocean of numbers, words, and ideas» are in demand and relevant [19]. Professional matrix research is extremely difficult, and time-consuming, but additional visualization of procedures at the auxiliary stage helps to overcome these difficulties and successfully cope with the «information explosion» [20].

\section{Diagnostic test}

The diagnostic test, as a working tool, has advantages:

- $\quad$ structures the dynamic flow of information;

- $\quad$ supports matrix research, increases its reliability, forms a vision, and helps formulate research hypotheses;

- $\quad$ integrated into specific corporate business processes [21]; 
- $\quad$ covers specific events and phenomena, indicators, takes into account trends, external influences, includes measurement scales, etc.;

- $\quad$ sets the sequence of mental operations based on the principle of differentiated continuity, i.e. linking each group of factors with targeted visualization techniques or visualization techniques;

- $\quad$ adjusted according to the phases of the product life cycle, customer segment, enterprise, industry economy, etc.

In the context of the issue under consideration, it is appropriate to use:

- horizontal line graphs, comparison diagrams of probabilistic processes («quantile quantile»), curves of life cycles and seasonal fluctuations, trends in commodity and currency markets, etc.;

- schemes, flowcharts, semantic networks that reflect the subject area of the process of entering and market promotion of goods, for example, within the framework of a state order or a portfolio of contracts. In the context of the hypothesis under study, it can be represented as a scheme that includes a certain combination of arrows, labels, signs, pointers, which helps to activate and form a logical conclusion by analogy with the practice of cognitive psychology (Fig. 3). If the process of accumulation and comprehension of knowledge in memory occurs through a system of associative connections between concepts [22], then the order of reasoning and drawing conclusions is set by signs, as easily perceived by information carriers.

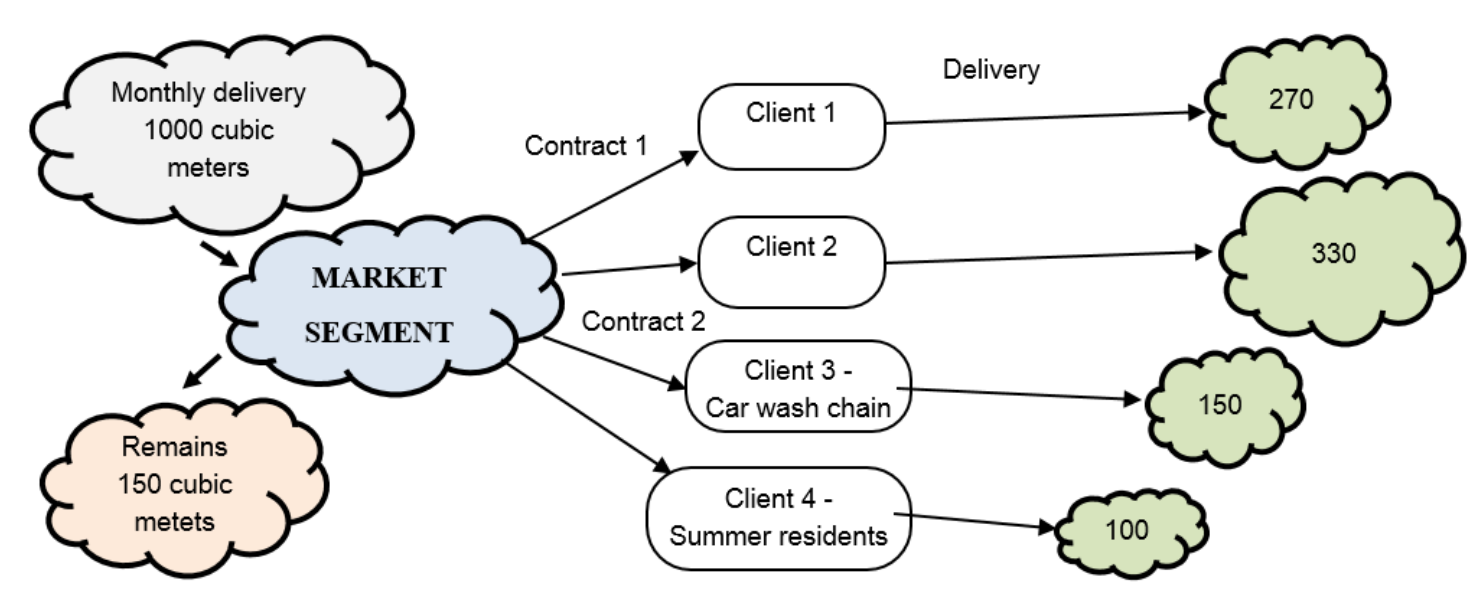

Fig. 3. Semantic network - «monthly product delivery plan»

So, when the first batch of goods in the amount of 1500 cubic meters is brought to the local water market, the scheme can emphasize the planned indicators of free sales for different groups of customers, specify the permissible volume of unrealized goods.

- concept map templates, Gantt charts, network and control charts help you assess the consequences of implementing the strategy and the prospects for increasing profitability, achieving the desired ratio of profit, revenue and cost dynamics;

- pie charts that can make data on the structure of the market clearly visible, when the objective heterogeneity of consumers always preserves the integrity of the customer base, which symbolizes the circle;

- radial (petal) diagrams allow you to quickly concentrate your thoughts on a group of parameters, and it is convenient to cover a set of interrelated indicators together. For example, to demonstrate the price levels for groups of customers; to quickly fix the indicators of the state of the market, to assess the readiness of the elements of the enterprise's potential for the development and implementation of the market positioning program (management, 
technology, personnel, financial, marketing, organizational, information), comparing with the control map;

- tree-like (mosaic) and «treemap» type diagrams record the minimum and maximum values of strategic indicators [23], set the search direction for internal resource reserves and external opportunities, and use color to focus on priorities;

- figure diagrams that combine the aesthetic appeal of the image, the rationality and utility of digital signal transmission, helping the specialist to concretize the arguments for choosing a solution at a glance, taking into account the emotional orientation of the nature of the new product (one of the features of environmentally significant strategies). Despite the roughness, simplicity, primitiveness and conventionality of the image, it is easy and fast to perceive the meaning of a homogeneous data flow when solving applied management problems, for example, the distribution of consumers by regional markets or other segments of the grouping (Fig. 4).
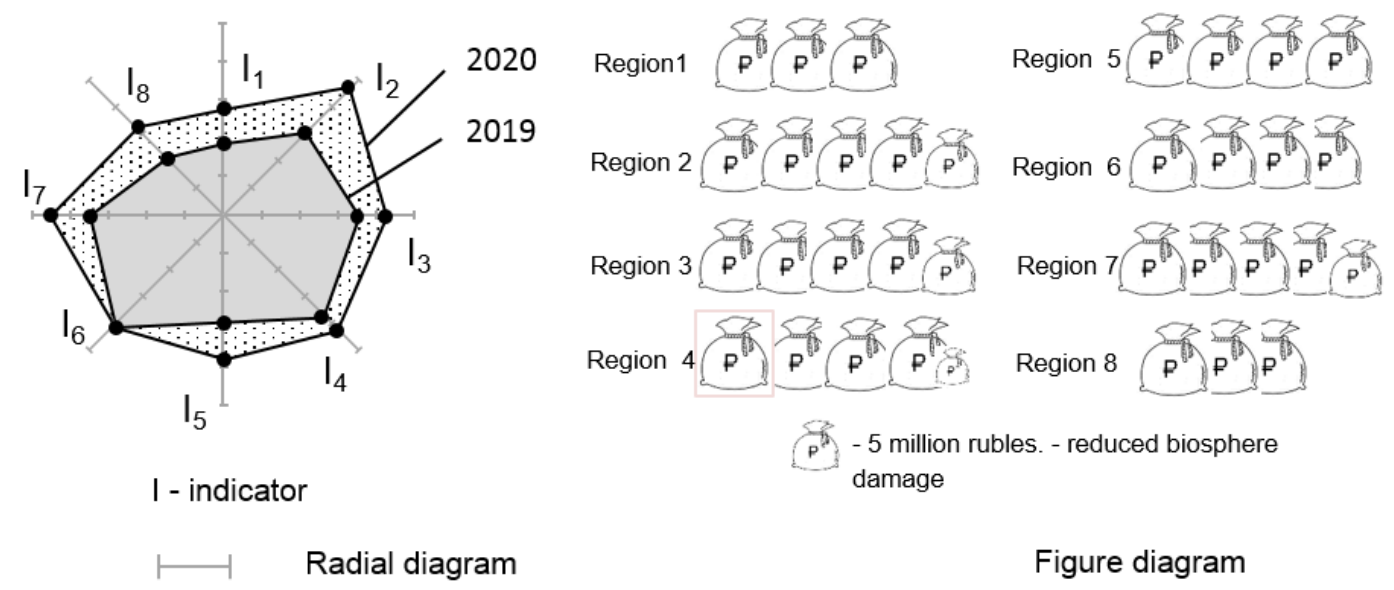

Figure diagram

Fig. 4. Options representation of SMZ-indicators in solving applied problems of strategic management

Visualization not only activates the visual system of the manager, helping to identify images, but also allows you to formulate research hypotheses in a reasoned way, to extract ideas from the target data array. Success is largely determined by the ability of a software developer to selectively select infographic techniques, taking into account the specifics of industry production or regional (territorial) features of management. Templates can reliably connect a wide range of criteria for evaluating the external and internal environment, help to mentally organize information and thereby overcome the limitations of the two-dimensional matrix [24]. A variety of visual forms contributes to a deeper understanding of the situation, a more objective, detailed and balanced choice of position.

In a rapidly changing competitive environment, uncertainty and risks are growing, which explains why often scientifically proven strategies do not produce the desired results in practice. The decision-making specialist is faced with constantly updated data, and this increases the relevance of supplementing the classical matrices with targeted adapted tests with a detailed content basis and rationally embedded visual images. Matrix research is a logical sequence of analytical operations that provide a complex process of obtaining new knowledge about the market situation, about the competitive position of the product being put on the market in coordination with the behavior of competitors, about the composition of factors influencing the choice of SMZ, about the centers of cost and profit formation (Fig. 5). 
A test is developed and presented to justify the optimal strategic choice in the course of a double matrix analysis (Fig. 6). The manager makes a choice if he gets the highest number of «yes» answers.

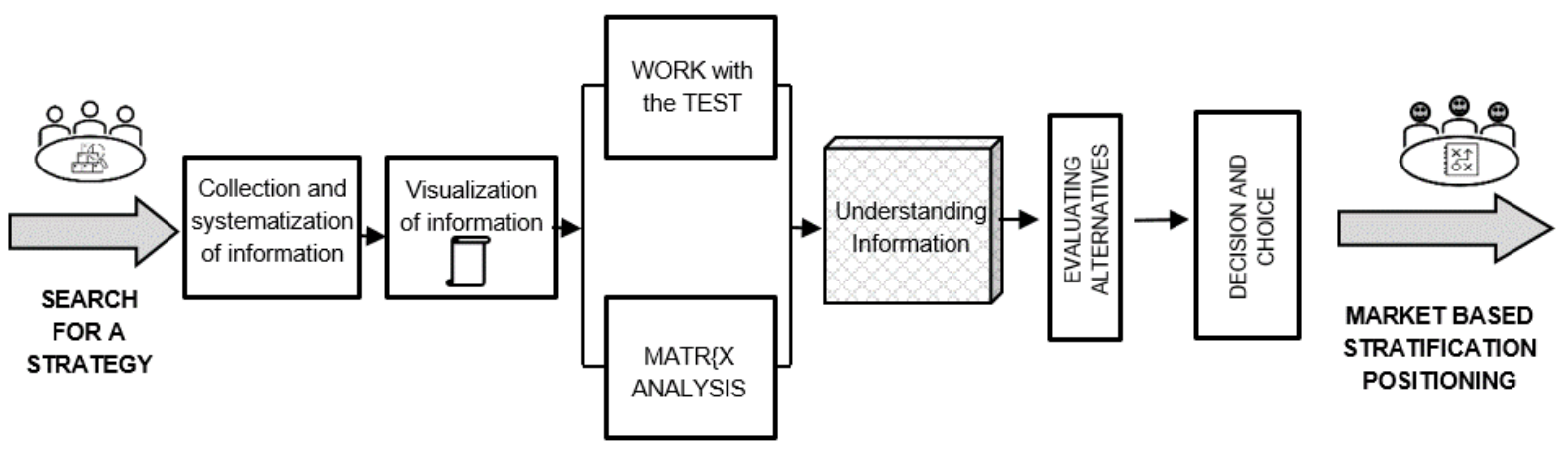

Fig. 5. The scheme of matrix visual research

\begin{tabular}{|c|c|c|c|}
\hline \multirow[t]{2}{*}{ TESTING ASPECTS } & \multirow[t]{2}{*}{ Type of visibility } & \multicolumn{2}{|c|}{ Answer } \\
\hline & & YES & NO \\
\hline $\begin{array}{l}\text { 1. MARKET } \\
\text { 1.1. Market concentration index less than } 45 \%\end{array}$ & \multirow{6}{*}{$\begin{array}{l}\text { 1. Operational information: } \\
\text { - illustration; } \\
\text { - formation of views; } \\
\text { - informing. } \\
\\
\text { 2. Background } \\
\text { - Create an intensity back- } \\
\text { ground around a meaningful } \\
\text { graphic image }\end{array}$} & & + \\
\hline $\begin{array}{l}\text { 1.2. The share of the leading competitor does not ex- } \\
\text { ceed } 15 \%\end{array}$ & & & + \\
\hline $\begin{array}{l}\text { 1.3. The relative market share is more than } 0.7 \text {, i.e. } \\
\text { very close to } 1.0 \text { (the market share of the enterprise in } \\
\text { relation to the leader) }\end{array}$ & & & + \\
\hline $\begin{array}{l}\text { 1.3. The growth rate of the market capacity is higher } \\
\text { than the sales growth rate by } 3-5 \% \text {, there is an unsat- } \\
\text { isfied demand }\end{array}$ & & + & \\
\hline $\begin{array}{l}\text { 1.4. Is it really possible to keep the share of the roar } \\
\text { for } 2-3 \text { years }\end{array}$ & & + & \\
\hline $\begin{array}{l}\text { 1.5. Is it realistic to increase the share of roar by } 1 \% \\
\text { within } 2-3 \text { years }\end{array}$ & & + & \\
\hline $\begin{array}{l}\text { 2. PRODUCT } \\
\text { 2.1. Meets the industry quality standard }\end{array}$ & \multirow{8}{*}{$\begin{array}{l}\text { 1. Structural: } \\
\text { - structure analysis; } \\
\text { - dynamics comparison; } \\
\text { - comparison with the plan, } \\
\text { norms, best values; } \\
\text { - designation of causes and } \\
\text { effects; } \\
\text { - focus on forecasts; } \\
\text { - identification of gaps. } \\
\text { 2. Continuity - the designa- } \\
\text { tion of key associative links } \\
\text { within the graphic image. } \\
\text { 3. Background } \\
\text { 4. Operational }\end{array}$} & + & \\
\hline $\begin{array}{l}\text { 2.2. A satisfactory level of recognition (for loyal cus- } \\
\text { tomers, at least } 20 \% \text { ) }\end{array}$ & & + & \\
\hline $\begin{array}{l}\text { 2.3. The presence of a clear competitive advantage } \\
\text { that contributes to the retention/increase of market } \\
\text { share }\end{array}$ & & + & \\
\hline $\begin{array}{l}\text { 2.4. Availability of the possibility of obtaining a state } \\
\text { order. Complies with federal national projects and } \\
\text { regional development programs }\end{array}$ & & + & \\
\hline $\begin{array}{l}\text { 2.5. High indicators of distribution of the company's } \\
\text { goods in the market (effective distribution networks } \\
\text { of goods) }\end{array}$ & & & + \\
\hline $\begin{array}{l}\text { 2.6. Low seasonality of sales: monthly sales volumes } \\
\text { are almost the same (maximum attractiveness) }\end{array}$ & & + & \\
\hline 2.7. Flexible pricing policy & & + & \\
\hline 2.8. Successful sales techniques & & & + \\
\hline
\end{tabular}




\begin{tabular}{|c|c|c|c|}
\hline $\begin{array}{l}\text { 3. RESOURCES } \\
\text { 3.1. There are economies of scale in sales: when pro- } \\
\text { duction is doubled, unit variable costs are reduced by } \\
\text { about } 20 \%\end{array}$ & \multirow{9}{*}{$\begin{array}{l}\text { 1. Distribution system: } \\
\text { - increase the level of data } \\
\text { availability; } \\
\text { - highlight the main item; } \\
\text { - enhanced perception; } \\
\text { - establishing a connection; } \\
\text { - quality of analysis; } \\
\text { - objectivity. } \\
\text { 2. Formalized: } \\
\text { - techniques for placing im- } \\
\text { ages and signs; } \\
\text { - focus on significant choice } \\
\text { factors and decision aspects; } \\
\text { - external design. } \\
\text { 3. Operational } \\
\text { 4. Background } \\
\text { 5. Structural }\end{array}$} & + & \\
\hline 3.2. The possibility of attracting investment (credit) & & + & \\
\hline $\begin{array}{l}\text { 3.3. The level of progressiveness of production tech- } \\
\text { nologies }\end{array}$ & & + & \\
\hline $\begin{array}{l}\text { 3.4. The level of progressiveness of production tech- } \\
\text { nologies }\end{array}$ & & & + \\
\hline 3.5. There is a resource for stimulating consumers & & + & \\
\hline $\begin{array}{l}\text { 3.6. Dynamics of key cash flows - the growth rate of } \\
\text { net profit outpaces the growth rate of revenue, which } \\
\text { in turn outpaces the growth rate of costs }\end{array}$ & & & + \\
\hline $\begin{array}{l}\text { 3.7. Availability of insurance and reserve funds: an- } \\
\text { nual reserve of } 30 \% \text { of net profit }\end{array}$ & & & + \\
\hline $\begin{array}{l}\text { 3.8. The rate of return exceeds the rate of inflation and } \\
\text { more than doubles the bank interest on deposits }\end{array}$ & & & + \\
\hline 3.9. Risk readiness: availability of an insurance fund & & + & \\
\hline TOTAL & - & +14 & -9 \\
\hline
\end{tabular}

Fig. 6. Test for justifying the optimal strategic choice in the course of a double matrix analysis of the market (compiled by the author)

The novelty of the approach consists in the development of the technique of matrix research of the market position of the product, based on modern tools and basic principles of visualization: 1) the integrity of the graphic representation; 2) the correspondence of the chosen metaphor to the problem being solved; 3) ensuring the dynamism of the image. This makes the test non-static, capable of being deployed and deepened as new knowledge and experience are accumulated. Embedded graphic, formula, and digital elements make «an exhaustive picture of the positions of strategic markers» [25], reflect the context, semantic connections, and increase the readability and clarity of the text perception [26]. What seems more important to us is not the illustrative function of operational visualization, but rather the ability to identify strategic gaps and their implications [27].

\section{Conclusion}

The peculiarity of matrix strategic analysis is manifested in the need to comprehend a wide range of constantly updated source data obtained from heterogeneous sources. The complexity and often inconsistency of the tasks to be solved require a deep understanding of their subject area, and the intensive growth of the array of figures, facts and arguments leads to the need to overcome the excess of information. The solution to this problem is critically important in the field of management and is seen in the possibility of supplementing the classic market research matrices with special diagnostic tests. Competent justification of the key areas of analysis and the choice of criteria for evaluating events focus the specialist's attention directly on the factors that determine the commercial success of the product promotion strategy, reduce the amount of unnecessary work, minimize subjective judgments and mistakes.

The rich class of graphical metaphors chosen for illustration simplifies analytical actions and the resource costs of performing them. The proposed technique of market research improves the theoretical apparatus of matrix analysis of the strategic planning system by:

- detailing the composition of operational information at the stage of preliminary analysis of the subject area of the task by three priorities - market, product, resources; 
- increasing the level of analytical validity of the strategy by specifying the selection criteria at the stage of discussing the classic strategic positions and choosing the option with the best conditionality;

- use of perceptible visualization techniques for individual entities and relationships, understanding the patterns of cash flow balance formation in each possible strategic zone, and fixing important facts in the field of view of a specialist.

Thanks to the development of interactive visualization tools, additional testing gives matrix analysis a number of advantages over other traditional strategic management methods. In particular, the accuracy of medium-and long-term budgeting increases, as well as the consistency coefficient of experts' work more than doubles, because they can set new research guidelines by receiving intermediate search results, thereby increasing the accuracy and objectivity of the result [5].

\section{References}

1. Burgelman RA, Floyd SW, Laamanen T, Mantere S, Vaara E, Whittington R. Strategy processes and practices: Dialogues and intersections. Strat Mgmt J. 2018; 1-28. https://doi.org/10.1002/smj.2741

2. Popovic A., Hackney R., Coelho P.S., Jaklic J. Towards business intelligence systems success: Effects of maturity and culture on analytical decision making // Decision Support Systems, 2012. - V. 54. - issue 1. - P.p. 729-739. DOI: 10.1016/j.dss.2012.08.017.

3. Gareev T. R., Belsky V. V. Matrixes of strategic groupings: from «old» criticism to new dimensions //Innovation, 2015. - № 2 (196). - P.p. 50-57.

4. Peters T., Waterman M. R. In Search of Perfection: Lessons from America's most successful companies //Strategic decisions and risk management, 2011. - № 1 (64). - P.p. 32-33.

5. Maksimov N.V., Golitsina O.L., Monankov K.V., Gavrilkina A.S. Methods of visual graph-analytical presentation and retrieval of scientific and technical texts // Scientific Vizualization, 2021. - V. 13. - issue 1. - P.p. 138-161, DOI: 10.26583/sv.13.1.10

6. Romanova I. K. Comparative analysis and modifications of visualization methods in parametric studies of control systems //Science and Education. Bauman Moscow State Technical University. Electronic Journal, 2017. - № 01. - Pp. 50-76. DOI: 10.7463/0117.0000926.

7. Bertin J. Semiology of graphics. Diagrams. Networks. Maps. Redlans: Esri Press, 2011. $-438 \mathrm{p}$.

8. Trubakova A.A., Trubakov A.O. Visual Analysis of Dynamic Changes in Structured Data on the Basis of Colour Markers // Scientific Visualization, 2020. - V. 12 - issue 4.- P.p. 85-97. DOI: $10.26583 /$ sv.12.4.08

9. Lupton R.C., Allwood J.M. Hybrid Sankey diagrams: Visual analysis of multidimensional data for understanding resource use // Resources, Conservation \& Recycling, 2017. № 124. - P.p.141-151.

10. Skau D., Harrison L., Kosara R. An evaluation of the impact of visual embellishments in bar charts // Proc. of Eurographics Conf. on Visualization, 2015. - V. 34. - №. 3. - P.p. 221230.

11. Goncharov V. M., Shalevskaya E. Yu. Strategic management zone as a unit of portfolio analysis of enterprise potential development // Ekonominfo, 2018. - V. 15.- № 1.- Pp. 22-27.

12. Gorshkova L. A., Poplavsky B. N. Tools of goal setting and formation of the enterprise development strategy // Economic analysis: theory and practice, 2008. - № 9 (114). - Pp. 2-6.

13. Arjen Y. Hoekstra, Ashok K. Chapagain, Maite M. Aldaya, Mesfin M. Mekonnen. The Water Footprint Assessment Manual: Setting the Global Standard. London, Washington DC, 2011. Available at:

http://waterfootprint.org/media/downloads/TheWaterFootprintAssessmentManual_2.pdf 
14. Steffen J., Jensen M., Pomeroy C.A., Burian S.J. Water Supply and Storm Water Management Benefits of Residential Rainwater Harvesting in U.S. Cities. // Journal of the American Water Resources Association, 2013. - V. 49, issue 4.- P.p. 810-824.

15. Blecken G.-T., Marsalek J., Viklander M. Laboratory Study of Stormwater Biofiltration in Low Temperatures: Total and Dissolved Metal Removals and Fates. Water, Air and Soil Pollution, 2011. - V. 219. - Pp. 303-317.

16. Kuznetsova E., Barchugova E., Brodach M. Rain water as a promising resource of public spaces // Buildings of High Technologies, 2018. - No. 3. - Pp. 48-54.

17. Zhu B., Chen H. Information visualization // Annual Review of Information Science and Technology, 2005. - V. 39. - issue 1. - Pp. 139-177.

18. Shklyar A.V. Evaluation of the practical applicability of visual research tools // Bulletin of the Bryansk State Technical University, 2019. - № 1 (74). - Pp. 69-76.

19. Aruldoss V., Lakshmi T.M., Venkatesan P.V. A survey on recent research in business intelligence // Journal of Enterprise information Management, 2014. - V. 27. - issue 6.- Pp. 831-866.

20. Gavrilova T. A., Alsuf'ev A. I., Grinberg E. Ya. Visualization of knowledge: criticism of the St. Gallen School and analysis of modern trends, 2017. - No. 3 (41). - P.p. 7-19. DOI: 10.17323/1998-0663.2017.3.7.19.

21. Sharma R., Mithas S., Konkanhalli F. Transforming decision-making processes: A research agenda for understanding the impact of business analytics on organization // European Journal of Information Systems, 2014. - V. 23. - issue 4.- P.p. 433-441.

23. Goldberg J., Helfman J., Beresniewicz J. From Research to Product: Integrating Treemaps into Enterprise Software [Электронный pecypc]. URL: http://2014.hci.international/files/HCII2014_Final_Program.pdf (дата обращения: 20.01.2021).

24. Egorova M. Yu. Development of an auxiliary test for choosing a company's development strategy based on the Ansoff matrix // Bulletin of the University, 2015. - № 13. - P.p. 30-34.

25. Akhmetshin E. M., Vasilev V. L., Mironov D. S., Zatsarinnaya E. I., Romanova M. V., Yumashev A. V. Internal Control System in Enterprise Management: Analysis and Interaction Matrices //European Research Studies Journal, 2018. - V. 21. - issue 2. - P.p. 728-740.

26. Laptev V.V., Orlov P.A., Dragunova O.V. Visualization of dynamic data structures using flowcharts in web analytics // Scientific and Technical Bulletin of SPbSPU. Computer science. Telecommunications. Management, 2017. , V. 10. - № 4. - P.p. 7-16. DOI: 10.18721/JCSTCS.10401.

27. Pfeffer J., Sutton R.I. Evidence-based management //Harvard business review, 2006. - V. 84. - № 1. - P.p. 62-74. 